\title{
Kako prebrojati konstitucijske izomere alkana
}

DOI: $10.15255 / K U I .2017 .055$

KUI-12/2018

Stručni rad

Prispjelo 28. prosinca 2017.

Prihvaćeno 3. siječnja 2018.

\section{N. Raos*}

Institut za medicinska istraživanja i medicinu rada, Ksaverska cesta 2, 10000 Zagreb

\begin{abstract}
Sažetak
Ključne riječi

Nastava kemije, ugljikovodici, konstitucijske formule, kemijska teorija grafova
\end{abstract}

Prebrojavanje konstitucijskih (strukturnih) izomera alkana lijepa je vježba kojom učenik stječe osjećaj za raznolikost kemijke strukture te ovladava vještinom pisanja kemijskih formula i sustavnih imena kemijskih spojeva. U članku je predložena jednostavna shema sustavnog prebrojavanja izomera temeljena na maksimalnoj dužini alifatskog lanca. Zadatak se može izvesti slaganjem šibica ili drugih štapića. U članku je dana konstrukcijska shema do molekule nonana (35 izomera).

\section{Uvod}

Povijest izomera ${ }^{1}$ počinje godine 1824 . kada su objavljene elementne analize dviju soli srebra. Obje su imale istu molekularnu formulu: AgCNO. No unatoč tome bilo je jasno kako je riječ o dvije tvari koje su analizirala dvojica kemičara, Justus von Liebig i Friedrich Wöhler. Njih je pak rasprava oko analize tih dviju soli zbližila, pa su zahvaljujući njima, tim solima, postali doživotni prijatelji. Prva je, Liebova sol bila "praskavo srebro", srebrov fulminat, a druga sol, ona Wöhlerova bila je srebrov cijanat. Pitanje jednakosti i nejednakosti tih dviju soli zbunjivala je i druge kemičare. Berzelius je mislio kako bi temelj razlike mogla biti "životna sila" (očito je najlakše protumačiti ono što ne razumijemo onime što ne znamo), no kada se 1830. godine susreo sa sličnom pojavom kod vinske kiseline (optički aktivna i optički neaktivna), shvatio je da dva spoja mogu imati istu (molekularnu) formulu, no različitu strukturu (konstituciju). Tako je u kemiju uveo novu pojavu, kojoj je 1832. godine dao ime izomerija - od grčkog isos - isto i meros - mjera.

Izomeri bi dakle bili takvi spojevi koji imaju istu "mjeru", tj. daju isti omjer kemijskih elemenata pri analizi. Prema toj široj definiciji svi spojevi s istom empirijskom formulom su izomeri, pa bi primjerice izomeri bili svi cikloalkani, jer im je molarni omjer ugljika i vodika $1: 2$, tj. opća formula $\left(\mathrm{CH}_{2}\right)_{n}$. No prema užoj definiciji izomeri su svi spojevi iste molekularne formule, poput alkana formule $\mathrm{C}_{5} \mathrm{H}_{12}$ ili monosaharida formule $\mathrm{C}_{6} \mathrm{H}_{12} \mathrm{O}_{6}$ (heksoze).

No dok su za otkriće izomerije zaslužni, razumije se, kemičari, za njihovo prebrojavanje zaslužni su matematičari.. ${ }^{2-4}$ Točnije, prvi sustavni algoritam za prebrojavanje izomera

* Dr. sc. Nenad Raos

e-pošta: raos@imi.hr dugujemo engleskom matematičaru Sir Arthuru Cayleyu (1821. - 1895.) koji se proslavio po otkriću matrica, geometrije u $n$ dimenzija te teorijom invarijanti. Četrdeset godina nakon što je Berzelius imenovao izomeriju kao pojavu Cayley je 1874. objavio znanstveni rad o matematičkoj teoriji izomera. ${ }^{5} \mathrm{Ne}$ samo da je uveo algoritam kojim su se mogli prebrojavati izomeri alkana te njihovih monosupstituiranih derivata, primjerice halida i monovalentnih alkohola, nego je uveo i novi koncept kako u kemiju tako i u matematiku. Riječ je naime u tome da je problem izomera shvatio kao problem grananja stabla, a sve to opet pretočio u opći pojam grafa, pa stoga Sir Cayleya možemo smatrati začetnikom primjene teorije grafova u kemiji, ${ }^{6-8}$ a njegov rad lijepim primjerom kemijske kombinatorike. ${ }^{9}$

Koliko je problem prebrojavanja izomera bio tvrd orah i za takovog vrsnog matematičara kakav je bio Sir Cayley neka nam kaže podatak da je 1880. godine Hermann uočio krivo prebrojavanje za izomere dodekana $\left(\mathrm{C}_{12} \mathrm{H}_{26}\right)$ i tridekana $\left(\mathrm{C}_{13} \mathrm{H}_{28}\right){ }^{10}$ dvije najveće formule na koje je Cayley primijenio svoj algoritam. Tek su 1931. Henze i Blair objavili znanstveni rad u kojem su prebrojali sve izomere alkana do 40 ugljikovih atoma, ${ }^{11}$ no i njihov je rezultat poslije ispravljen za alkan $\mathrm{C}_{19} \mathrm{H}_{40}$, koji je korigiran za još tisuću pronađenih konstitucijskih izomera. ${ }^{12}$ Opće se rješenje problema pojavilo istom 1937. godine s Pólyinim enumeracijskim teoremom, ${ }^{13}$ no rad na algoritmima za prebrojavanje i konstrukciju izomera, kako alkana tako i drugih spojeva, ${ }^{14}$ time nije završen: znanost nema granica, pa tako ni na tom području istraživanja.

Takav bi nas slijed događaja trebao manje čuditi kada se suočimo s enormnim brojem konstitucijskih izomera (tablica 1). Sa svakim novim ugljikovim atomom broj se izomera povećava oko $2-2,5$ puta. Alkan s 10 ugljikovih atoma ima 75 izomera, onaj s 20 366.319, s 30 4.111.846.763, 
a s 40 ugljikovih atoma više od 62 bilijuna izomera (točno: 62.481.801.147.341). Broj alkana formule $\mathrm{C}_{80} \mathrm{H}_{162}$ dosiže vrijednost $10^{32} \cdot{ }^{14}$

Tablica 1 - Broj konstitucijskih izomera alkana (ref. 14, p. 38)

Table 1 - Number of constitutional alkane isomers (Ref. 14, p. 38)

\begin{tabular}{|c|c|c|}
\hline $\begin{array}{l}\text { Br. C atoma } \\
\text { No. of C atoms }\end{array}$ & $\begin{array}{l}\text { Osnovni alkan } \\
\text { Parent alkane }\end{array}$ & $\begin{array}{c}\text { Broj izomera } \\
\text { Number of isomers }\end{array}$ \\
\hline 1 & $\begin{array}{l}\text { metan } \\
\text { methane }\end{array}$ & 1 \\
\hline 2 & $\begin{array}{l}\text { etan } \\
\text { ethane }\end{array}$ & 1 \\
\hline 3 & $\begin{array}{l}\text { propan } \\
\text { propane }\end{array}$ & 1 \\
\hline 4 & $\begin{array}{l}\text { butan } \\
\text { butane }\end{array}$ & 2 \\
\hline 5 & $\begin{array}{l}\text { pentan } \\
\text { pentane }\end{array}$ & 3 \\
\hline 6 & $\begin{array}{l}\text { heksan } \\
\text { hexane }\end{array}$ & 5 \\
\hline 7 & $\begin{array}{l}\text { heptan } \\
\text { heptane }\end{array}$ & 9 \\
\hline 8 & $\begin{array}{l}\text { oktan } \\
\text { octane }\end{array}$ & 18 \\
\hline 9 & $\begin{array}{l}\text { nonan } \\
\text { nonane }\end{array}$ & 35 \\
\hline 10 & $\begin{array}{l}\text { dekan } \\
\text { decane }\end{array}$ & 75 \\
\hline 11 & $\begin{array}{l}\text { undekan } \\
\text { undecane }\end{array}$ & 159 \\
\hline 12 & $\begin{array}{l}\text { dodekan } \\
\text { dodecane }\end{array}$ & 355 \\
\hline 13 & $\begin{array}{l}\text { tridekan } \\
\text { tridecane }\end{array}$ & 802 \\
\hline 14 & $\begin{array}{l}\text { tetradekan } \\
\text { tetradecane }\end{array}$ & 1.858 \\
\hline 15 & $\begin{array}{l}\text { pentadekan } \\
\text { pentadecane }\end{array}$ & 4.347 \\
\hline 16 & $\begin{array}{l}\text { heksadekan } \\
\text { hexadecane }\end{array}$ & 10.359 \\
\hline 17 & $\begin{array}{l}\text { heptadekan } \\
\text { heptadecane }\end{array}$ & 24.894 \\
\hline 18 & $\begin{array}{l}\text { oktadekan } \\
\text { octadecane }\end{array}$ & 60.523 \\
\hline 19 & $\begin{array}{l}\text { nonadekan } \\
\text { nonadecane }\end{array}$ & 148.284 \\
\hline 20 & $\begin{array}{l}\text { eikosan (eikozan) } \\
\text { eicosane }\end{array}$ & 366.319 \\
\hline
\end{tabular}

Što radimo s alkanima većeg broja ugljikovih atoma (N) trebat će nam složeniji algoritam da bismo im prebrojali izomere. Da bi se napisali svi izomeri butana $(N=2)$ ili pentana $(N=3)$, dovoljno je malo mašte, uz poznavanje zakona kemijskog spajanja, razumije se. No za prebrojavanje izomera viših alkana potreban je algoritam, potrebno je uvesti sustavan pristup. Bez njega nam se može dogoditi da neke izomere ispustimo, dok druge možda i dvaput prebrojimo. Ovdje sam predložio jedan takav sustav koji je lako shvatljiv, a zbog načina njegova izvođenja može biti i zabavan.

\section{Slaganje izomera šibicama}

Metoda prebrojavanja konstitucijskih izomera koju predlažem temelji se na prikazu grananja ugljikova lanca s pomoću šibica. Svaka šibica odgovara vezi između dva ugljikova atoma, broj šibica definira topološku udaljenost, a cijela slagalina predstavlja graf (kenogram) molekule. Izomeri alkana nemaju samo isti broj atoma nego i isti broj veza $\mathrm{C}-\mathrm{C}$, pa se svi izomeri butana (tablica 2) mogu složiti od tri, svi izomeri pentana od četiri, svi izomeri heksana od pet šibica i tako dalje. Uzmimo primjer pentana (tablica 3). Četiri šibice u nizu (bez grananja) predočavaju molekulu pentana, tri u nizu s jednom pridodatom odgovaraju molekuli izopentana (2-metilbutana), a dvije s dvjema pridodanim šibicama molekuli neopentana (2,2-dimetilpropana). Važno je uočiti pravilo da duljina nijednog lanca ne smije premašivati dužinu osnovnog lanca, lanca na koji se vežu supstituenti. Najduži (jedini) lanac u molekuli pentana ima topološku dužinu 4, u molekuli 2-metilbutana imamo dva lanca dužine 3 (uz jedan lanac dužine 2), a u molekuli 2,2-dimetilpropana šest lanaca dužine 2.

Slično vrijedi i za izomere heksana (tablica 4), no sada imamo dva izomera s maksimalnom dužinom lanca $4(4+1)$, tj. 2-metilpentan i 3-metilpentan te dva izomera s maksimalnom dužinom lanca $3(3+2)-2,2$-dimetilbutan i 2,3-dimetilbutan. Pri izomer dimetilbutana $(3+2)$ ima tri, a drugi 4 lanca (puta) dužine 3.

Heptan ima devet izomera (tablica 5), koji su prikazani na slici 1. Kod oktana (tablica 6) pojavljuje se izomer

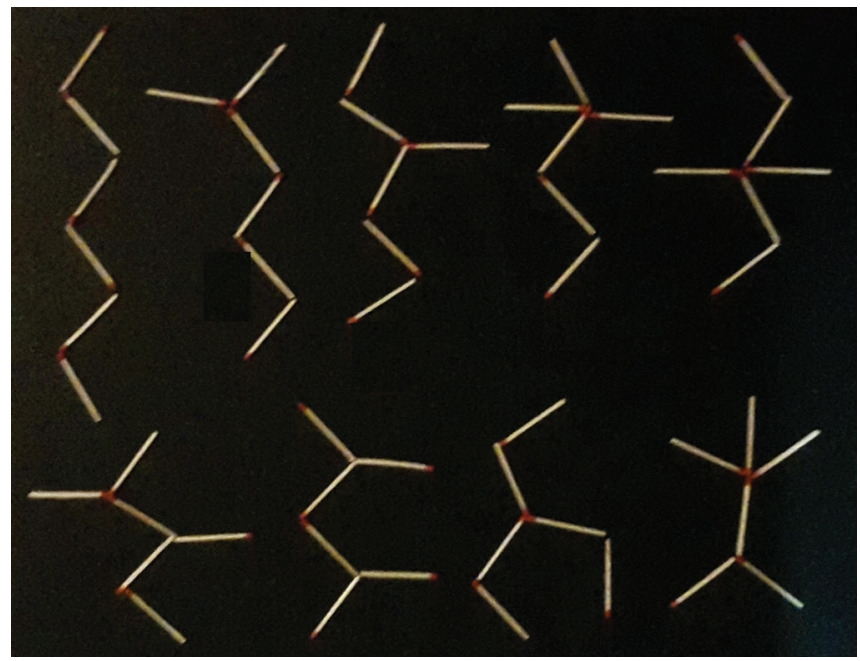

Slika 1 - Heptan i njegovi izomeri: heptan $(6+0)$, 2-metilheksan, 3-metilheksan $(5+1)$, 2,2-dimetilpentan, 3,3-dimetilpentan, 2,3-dimetilpentan, 2,4-dimetilpentan, 3-etilpentan $(4+2)$ i 2,2,3-trimetilbutan $(3+3)$

Fig. 1 - Heptane and its isomers: heptane $(6+0), 2$-methylhexane, 3-methylhexane $(5+1)$, 2,2-dimethylpentane, 3,3-dimethylpentane, 2,3-dimethylpentane, 2,4-dimethylpentane, 3-ethylpentane $(4+2)$, and 2,2,3-trimethylbutane $(3+3)$ 
s više supstuenata od maksimalne dužine lanca $(3+4)$, 2,2,3,3-tetrametilbutan. Potrudio sam se da iznađem sve izomere nonana (tablica 7), pa stoga mogu biti siguran kako predložena konstrukcijska shema funkcionira za molekule alkana do barem devet ugljikovih atoma.

Tablica 2 - Izomeri butana

Table 2 - Butane isomers

\begin{tabular}{c|c|c}
\hline $\begin{array}{c}\text { Maks. topološka udaljenost } \\
\text { Max. topological distance }\end{array}$ & $\begin{array}{c}\text { Shema slaganja } \\
\text { Construction } \\
\text { scheme }\end{array}$ & $\begin{array}{c}\text { Br. izomera } \\
\text { No. of isomers }\end{array}$ \\
\hline 3 & $3+0$ & 1 \\
2 & $2+1$ & 1 \\
\hline
\end{tabular}

Tablica 3 - Izomeri pentana

Table 3 - Pentane isomers

\begin{tabular}{c|c|c}
\hline $\begin{array}{c}\text { Maks. topološka udaljenost } \\
\text { Max. topological distance }\end{array}$ & $\begin{array}{c}\text { Shema slaganja } \\
\text { Construction } \\
\text { scheme }\end{array}$ & $\begin{array}{c}\text { Br. izomera } \\
\text { No. of isomers }\end{array}$ \\
\hline 4 & $4+0$ & 1 \\
3 & $3+1$ & 1 \\
2 & $2+2$ & 1 \\
\hline
\end{tabular}

Tablica 4 - Izomeri heksana

Table 4 - Hexane isomers

\begin{tabular}{c|c|c}
\hline $\begin{array}{c}\text { Maks. topološka udaljenost } \\
\text { Max. topological distance }\end{array}$ & $\begin{array}{c}\text { Shema slaganja } \\
\text { Construction } \\
\text { scheme }\end{array}$ & $\begin{array}{c}\text { Br. izomera } \\
\text { No. of isomers }\end{array}$ \\
\hline 5 & $5+0$ & 1 \\
4 & $4+1$ & 2 \\
3 & $3+2$ & 2 \\
\hline
\end{tabular}

Tablica 5 - Izomeri heptana

Table 5 - Heptane isomers

\begin{tabular}{c|c|c}
\hline $\begin{array}{c}\text { Maks. topološka udaljenost } \\
\text { Max. topological distance }\end{array}$ & $\begin{array}{c}\text { Shema slaganja } \\
\text { Construction } \\
\text { scheme }\end{array}$ & $\begin{array}{c}\text { Br. izomera } \\
\text { No. of } \\
\text { isomers }\end{array}$ \\
\hline 6 & $6+0$ & 1 \\
5 & $5+1$ & 2 \\
4 & $4+2$ & 5 \\
3 & $3+3$ & 1 \\
\hline
\end{tabular}

Tablica 6 - Izomeri oktana

Table 6 - Octane isomers

\begin{tabular}{c|c|c}
\hline $\begin{array}{c}\text { Maks. topološka udaljenost } \\
\text { Max. topological distance }\end{array}$ & $\begin{array}{c}\text { Shema slaganja } \\
\text { Construction } \\
\text { scheme }\end{array}$ & $\begin{array}{c}\text { Br. izomera } \\
\text { No. of } \\
\text { isomers }\end{array}$ \\
\hline 7 & $7+0$ & 1 \\
6 & $6+1$ & 3 \\
5 & $5+2$ & 7 \\
4 & $4+3$ & 6 \\
3 & $3+4$ & 1 \\
\hline
\end{tabular}

Tablica 7 - Izomeri nonana

Table 7 - Nonane isomers

\begin{tabular}{c|c|c}
\hline $\begin{array}{c}\text { Maks. topološka udaljenost } \\
\text { Max. topological distance }\end{array}$ & $\begin{array}{c}\text { Shema slaganja } \\
\text { Construction } \\
\text { scheme }\end{array}$ & $\begin{array}{c}\text { Br. izomera } \\
\text { No. of } \\
\text { isomers }\end{array}$ \\
\hline 8 & $8+0$ & 1 \\
7 & $7+1$ & 3 \\
6 & $6+2$ & 9 \\
5 & $5+3$ & 14 \\
4 & $4+4$ & 8 \\
\hline
\end{tabular}

\section{Izvođenje na nastavi}

Mislim da bi prebrojavanje konstitucijskih izomera metodom koju sam predložio bilo učenicima zabavno jer se sve na kraju svodi na igru slaganja štapića. Konstrukcija izomera viših alkana je međutim komplicirana, pa u pristupu valja biti metodičan. Stoga je najbolje slijediti predloženu shemu konstrukcije prema najvećoj dužini lanaca ili, još bolje, podijeliti zadatak po skupinama učenika, recimo tako da jedni slažu izomere nonana tipa $6+2$, drugi tipa $5+3$, a treći $4+4$. Radi konačne provjere ime svakog izomera treba napisati u egzaktnoj IUPAC-ovoj nomenklaturi (najbolje na listić papira), pa onda vidjeti nisu li se pojavila dva spoja istog imena. Tako se zadatak prebrojavanja izomera pretvara i u vježbu ovladavanja kemijskom nomenklaturom.

Zadatak se može pretvoriti i u natjecanje dviju ili više ekipa učenika, no učenici moraju već biti izvježbani u prebrojavanju izomera. Naročito bi zanimljivo (i zahtjevno) bilo prebrojavanje izomera dekana $(N=75)$, pa i viših alkana za koje ovdje nije navedena shema slaganja. To bi s jedne strane bila provjera algoritma predloženog u ovome članku, a s druge prilika učenicima da se iskušaju u istraživačkom radu. 


\section{Literatura \\ References}

1. D. Grdenić, Povijest kemije, Novi Liber i Školska knjiga, Zagreb, 2001., str. 607-611.

2. D. H. Rouvray, Isomer enumeration methods, Chem. Soc. Rev. 3 (1974) 355-372, doi: https://doi.org/10.1039/ CS9740300355.

3. D. H. Rouvray, The pioneers of isomer enumeration, Endeavour 34 (1975) 28-33, doi: https://doi.org/10.1016/01609327(75)90065-4.

4. J. V. Knop, W. R. Müller, Ž. Jeričević, N. Trinajstić, Computer enumeration and generation of trees and rooted trees, J. Chem. Inf. Comput. Sci. 21 (2) (1981) 91-99, doi: https:// doi.org/10.1021/ci00030a009.

5. A. Cayley, On the mathematical theory of isomers, Phil. Mag. 47 (1874) 444-447.

6. N. Raos, Što je dvodimenzijska struktura, Nove Slike iz kemije - priručnik kemije u nastavi, (ur. N. Raos), Školska knjiga i Hrvatsko kemijskog društvo, Zagreb, 2004., str. 63-74.

7. N. Raos, Što nam mogu reći vrelišta alkana?, Kem. Ind. 65 (3-4) (2016) 175-178, doi: https://doi.org/10.15255/
KUI.2015.039.

8. A. Miličević, Grafovi u kemiji, Priroda 101 (12) (2012) 38-41.

9. F. M. Brückler, Kombinatorika u kemiji, Kem. Ind. 65 (7-8) (2016) 401-405, doi: https://doi.org/10.15255/ KUI.2016.010.

10. F. Hermann, Ueber das Problem, die Anzahl der Isomeren Paraffine der Formel $\mathrm{C}_{n} \mathrm{H}_{2 n+2}$ zu bestimmen, Chem. Ber. 13 (1880) 792, doi: https://doi.org/10.1002/ cber.188001301222.

11. H. R. Henze, C. M. Blair, The number of isomeric hydrocarbons of the methane series, J. Chem. Soc. 53 (1931) 3077 3085, doi: https://doi.org/10.1021/ja01359a034.

12. D. Perry, The number of structural isomers of certain homologs of methane and methanol, J. Am. Chem. Soc. 54 (7) (1932) 2918-2920, doi: https://doi.org/10.1021/ ja01346a035.

13. G. Pólya Kombinatorische Anzahlbestimmungen für Gruppen, Graphen und chemische Verbindungen, Acta Math. 68 (1937) 145-254, doi: https://doi.org/10.1007/BF02546665.

14. J. V. Knop, W. R. Müller, K. Szymanski, N. Trinajstić, Computer generation of certain classes of molecules, SKTH/Kemija u industriji, Zagreb, 1985.

\section{SUMMARY \\ How to Enumerate Constitutional Isomers of Alkanes \\ Nenad Raos}

Enumeration of isomers, especially isomers of alkanes, is very instructive in teaching organic chemistry because it helps the students to gain greater proficiency in writing chemical formulas and systematic chemical names, as well as familiarizes them with the vast diversity of molecular structures. In this paper, a systematic approach for the construction of constitutional (structural) isomers of alkanes is described. It is based on grouping the isomers by their maximal chain length. The best way to apply this in the classroom is to use short sticks, e.g. matches, for the construction of alkane kenograms. The task of isomer construction should be organized as teamwork in a competitive manner. The approach is illustrated by enumerating isomers from $\mathrm{C}_{4}$ to $\mathrm{C}_{9}$.

\section{Keywords}

Chemistry education, hydrocarbons, constitutional formulas, chemical graph theory

Institute for Medical Research and

Occupational Health, Ksaverska c. 2

10000 Zagreb, Croatia
Professional paper

Received December 28, 2017 Accepted January 3, 2018 